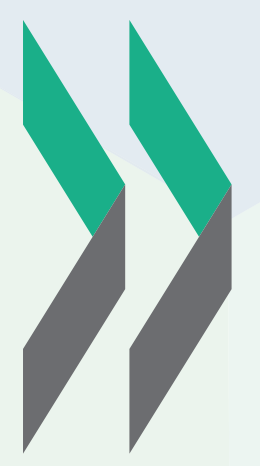

\title{
Collaborative problem solving
}

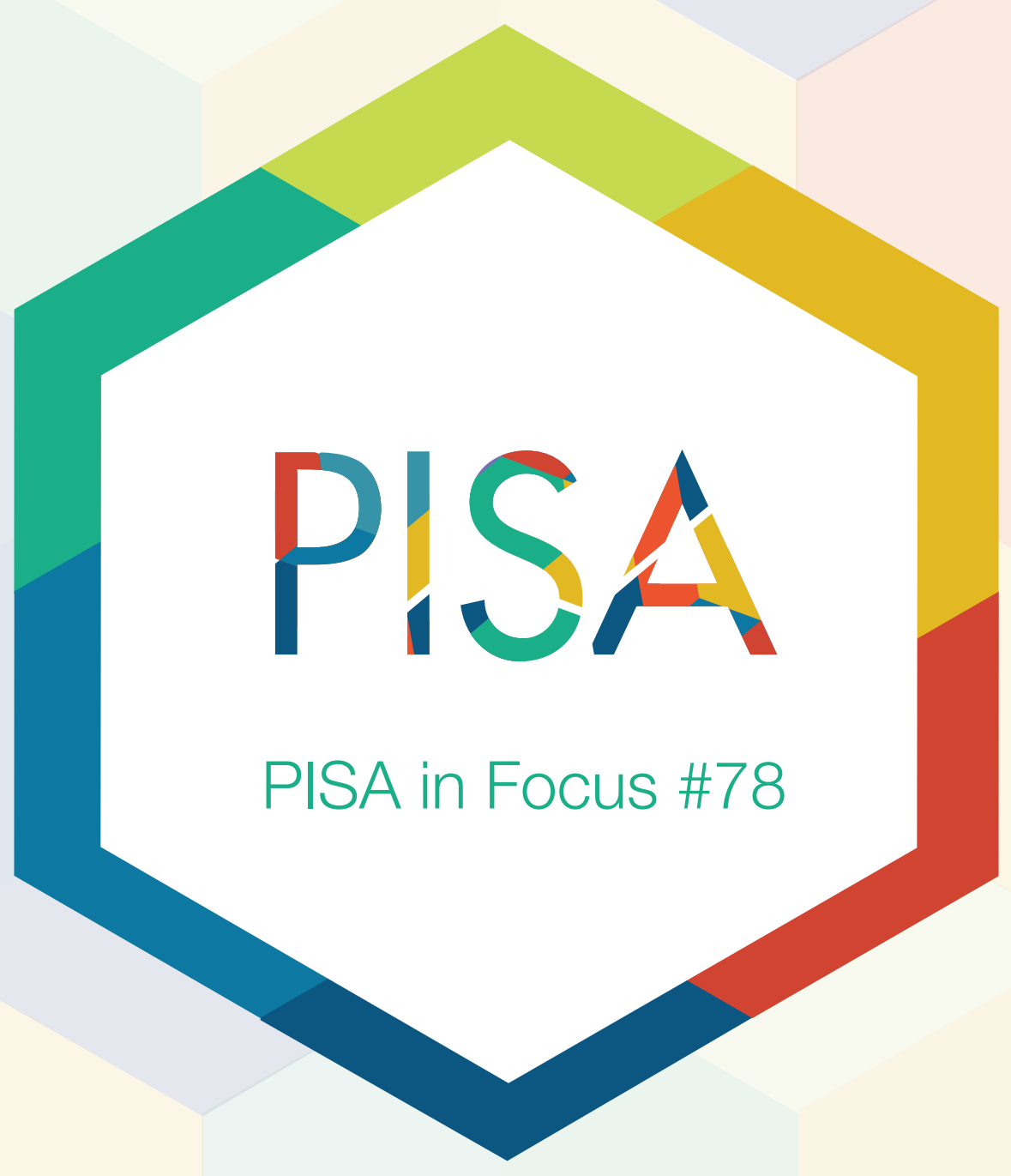




\section{What the data tell us}

\section{Student performance in collaborative problem solving}

- Students in Singapore score higher in collaborative problem solving than students in all other participating countries and economies, followed by students in Japan.

- On average across OECD countries, $28 \%$ of students are able to solve only straightforward collaborative problems, if any at all. By contrast, fewer than one in six students in Estonia, Hong Kong (China), Japan, Korea, Macao (China) and Singapore is a low achiever in collaborative problem solving.

- Across OECD countries, $8 \%$ of students are top performers in collaborative problem solving, meaning that they can maintain an awareness of group dynamics, ensure team members act in accordance with their agreed-upon roles, and resolve disagreements and conflicts while identifying efficient pathways and monitoring progress towards a solution.

- Collaborative problem-solving performance is positively related to performance in the core PISA subjects (science, reading and mathematics), but the relationship is weaker than that observed among those other domains.

- Students in Australia, Japan, Korea, New Zealand and the United States perform much better in collaborative problem solving than would be expected based on their scores in science, reading and mathematics.

\section{Student demographics and collaborative problem solving}

- Girls perform significantly better than boys in collaborative problem solving in every country and economy that participated in the assessment. On average across OECD countries, girls score 29 points higher than boys. The largest gaps - of over 40 points - are observed in Australia, Finland, Latvia, New Zealand and Sweden; the smallest gaps - of less than 10 points - are observed in Colombia, Costa Rica and Peru. This contrasts with the PISA 2012 assessment of individual problem solving, where boys generally performed better than girls.

- Performance in collaborative problem solving is positively related to students' and schools' socio-economic profile, although this relationship is weaker than the relationship between socio-economic profile and performance in the three core PISA subjects.

- There are no significant performance differences between advantaged and disadvantaged students, or between immigrant and non-immigrant students, after accounting for performance in science, reading and mathematics. But girls still score 25 points higher than boys after accounting for performance in the three core PISA subjects.

\section{Students' attitudes towards collaboration}

- Students in every country and economy have generally positive attitudes towards collaboration. Over $85 \%$ of students, on average across OECD countries, agree with the statements "I am a good listener", "I enjoy seeing my classmates be successful", "I take into account what others are interested in", "I enjoy considering different perspectives", and "I enjoy co-operating with peers".

- Girls in almost every country and economy tend to value relationships more than boys, meaning that girls agree more often than boys that they are good listeners, enjoy seeing their classmates be successful, take into account what others are interested in, and enjoy considering different perspectives.

- Boys in the majority of countries and economies tend to value teamwork more than girls, meaning that boys agree more often than girls that they prefer working as part of a team to working alone, find that teams make better decisions than individuals, find that teamwork raises their own efficiency, and enjoy co-operating with peers.

- Advantaged students in almost every country and economy tend to value relationships more than disadvantaged students, while disadvantaged students in most countries and economies tend to value teamwork more than advantaged students.

- After accounting for performance in the three core PISA subjects, gender, and socio-economic status, the more students value relationships, the better they perform in collaborative problem solving. A similar relationship is observed the more students value teamwork.

\section{Student activities, school policies and collaboration skills}

- Attitudes towards collaboration are generally more positive as students engage in more physical activity or attend more physical education classes per week. 
Countries/economies with a mean performance/relative performance above the OECD average

Countries/economies with a mean performance/relative performance not significantly different from the OECD average

Countries/economies with a mean performance/relative performance below the OECD average

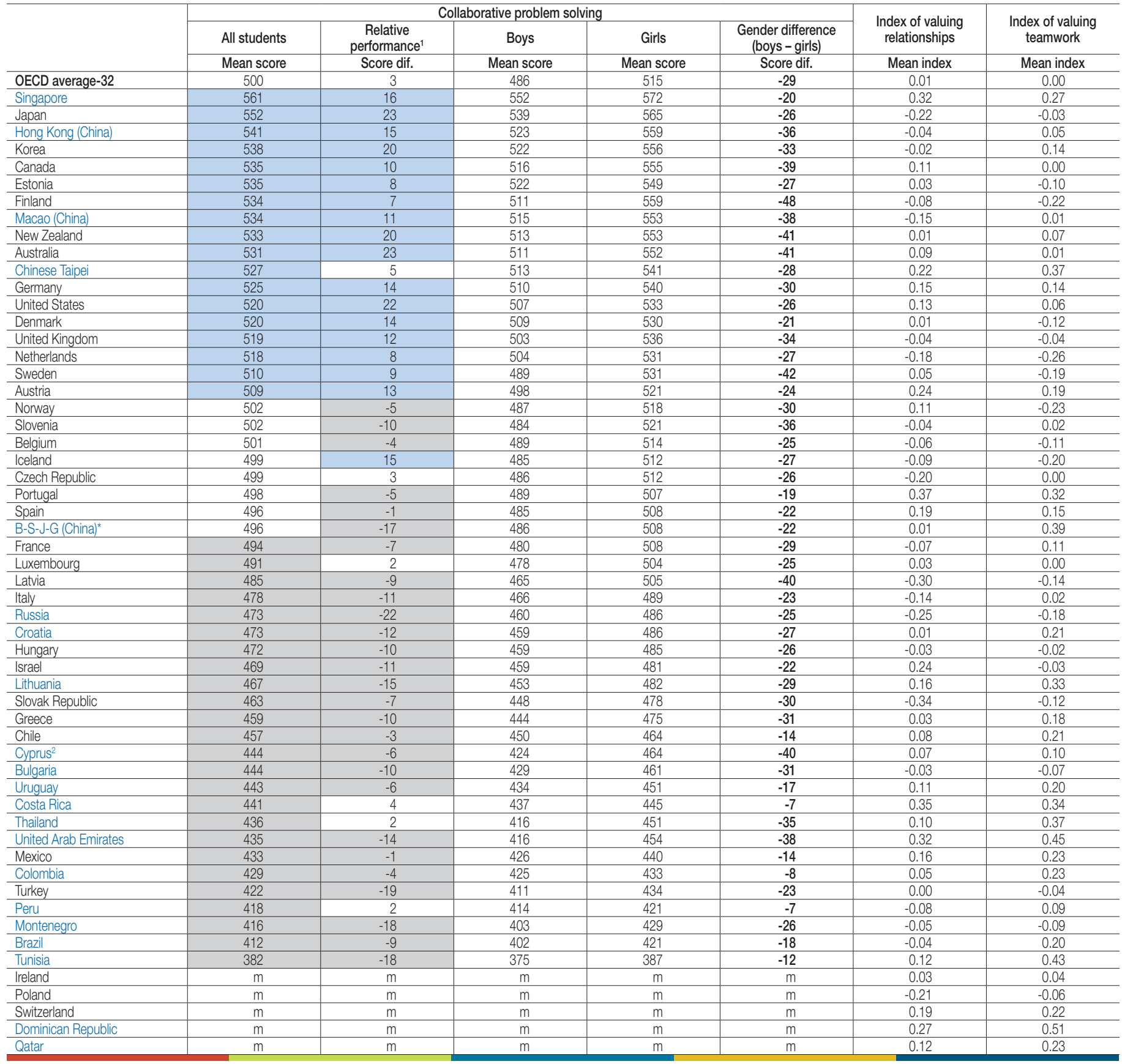

* B-S-J-G (China) refers to the four PISA-participating Chinese provinces and municipalities: Beijing, Shanghai, Jiangsu and Guangdong.

1. Relative scores are the residuals obtained from a pooled linear regression, across all participating countries/economies, of the performance in collaborative problem solving over performance in science, reading and mathematics.

2. Note by Turkey: The information in this document with reference to "Cyprus" relates to the southern part of the Island. There is no single authority representing both Turkish and Greek Cypriot people on the Island. Turkey recognises the Turkish Republic of Northern Cyprus (TRNC). Until a lasting and equitable solution is found within the context of the United Nations, Turkey shall preserve its position concerning the "Cyprus issue".

Note by all the European Union Member States of the OECD and the European Union: The Republic of Cyprus is recognised by all members

of the United Nations with the exception of Turkey. The information in this document relates to the area under the effective control of the Government of the Republic of Cyprus.

Note: At the country/economy level, values that are statistically significant are marked in bold (see Annex A3)

Countries and economies are ranked in descending order of the mean collaborative problem-solving score.

Source: OECD, PISA 2015 Database, Tables V.3.2, V.3.9a, V.4.3a and V.5.1. 
- Students who play video games outside of school score slightly lower in collaborative problem solving than students who do not play video games, on average across OECD countries, after accounting for performance in the three core PISA subjects, gender, and students' and schools' socio-economic profile. But students who access the Internet, chat or social networks outside of school score slightly higher than other students.

- Students who work in the household or take care of other family members value both teamwork and relationships more than other students.

\section{Collaborative schools}

- On average across OECD countries, students who reported not being threatened by other students score 18 points higher in collaborative problem solving than students who reported being threatened at least a few times per year. Students also score 11 points higher for every 10 percentage-point increase in the number of schoolmates who reported that they are not threatened by other students.

- Students score higher in collaborative problem solving when they or their schoolmates reported that teachers treat students fairly, even after accounting for their performance in science, reading and mathematics.

\section{Many school subjects provide opportunities to cultivate skills in and positive attitudes towards collaboration.}

Collaboration skills can be taught and practiced in cognitive subjects, such as science, reading and mathematics: students can work and present in groups and can help each other learn the subject. However, much of the effort to master the material taught is typically made individually by the student. In contrast, collaboration is vital to many activities in physical education class, most obviously team sports, which require individuals to work together in groups to achieve a common goal.

Physical education class and performance in collaborative problem solving, by gender Collaborative problem-solving performance, OECD average

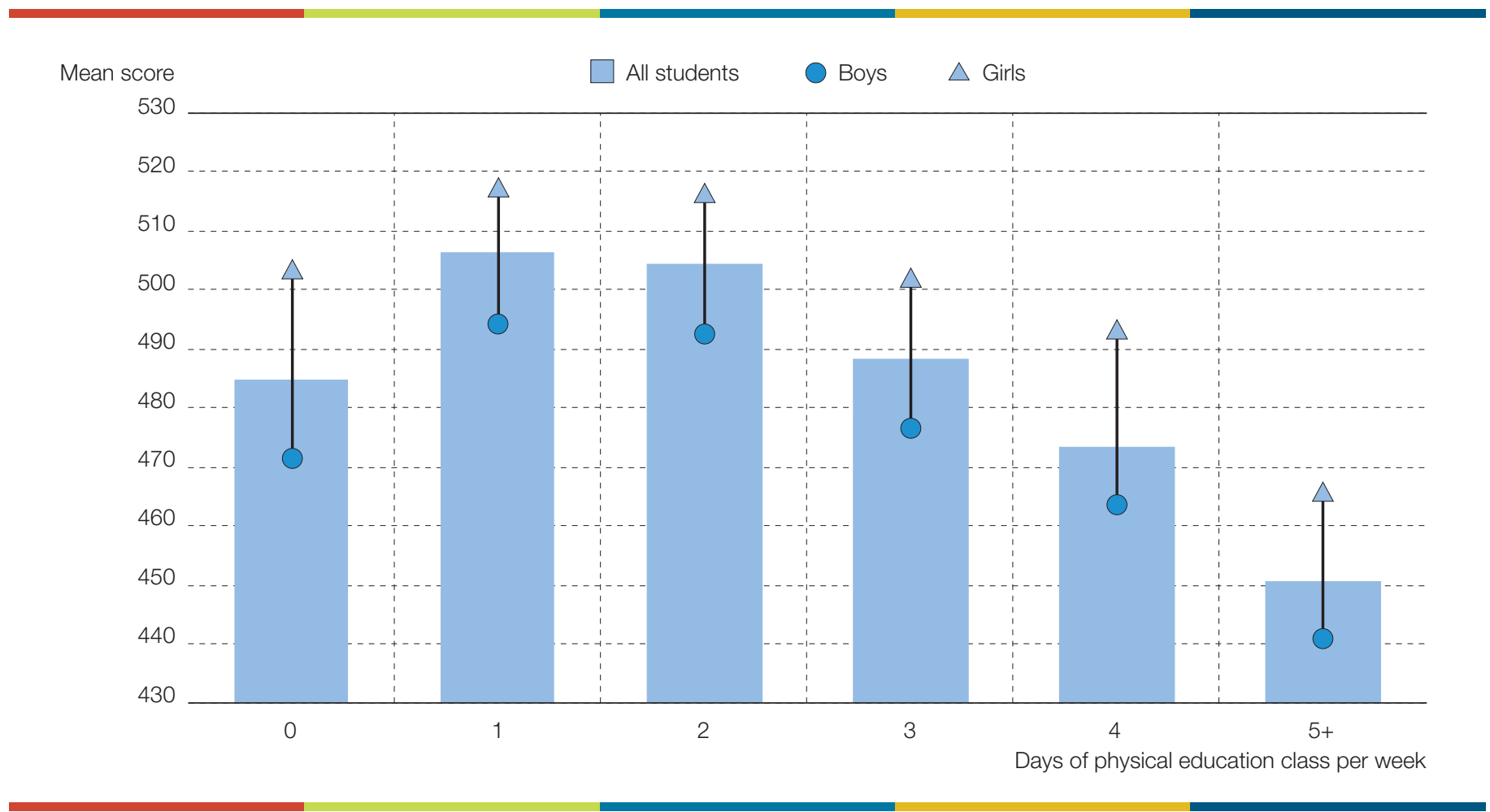

Source: OECD, PISA 2015 Database, Table V.6.1c. 
However, there is variation across countries in what is emphasised in physical education class. Some countries, including Finland and Japan, emphasise collaboration instead of competition in physical education class; other countries, such as Germany, Latvia, Hungary and the United Kingdom, place greater emphasis on competition and attaining one's personal best. Unfortunately, cross-sectional data from PISA cannot indicate which approach is more effective at developing collaboration skills.

What the data do show, though, is that students who attend physical education class once or twice per week score highest in collaborative problem solving. After accounting for performance in the three core PISA subjects, students who attend between zero and three days of physical education class per week score similarly, and score above students who attend four or more days per week.

\section{Students can be encouraged to mingle with others from different backgrounds.}

Previous PISA volumes have consistently documented that socio-economically advantaged students perform better in science, reading and mathematics than disadvantaged students. This is also true for performance in collaborative problem solving.

However, this relationship with socio-economic status is not consistently observed across education systems when looking solely at the collaborative aspect of students' collaborative problem-solving scores (i.e. once performance in science, reading and mathematics is accounted for). If anything, students of lower socio-economic status often do better than students of higher socio-economic status relative to their performance in the three core PISA subjects - although this relationship is highly variable across education systems.

In other words, there is no clear relationship between socio-economic status and students' ability to work productively with others. Disadvantaged students are more likely to value teamwork, perhaps because they value more the extra boost that teamwork can bring to their own performance. Likewise, there are no large differences between the collaborative skills of immigrant and non-immigrant students.

One of the demographic factors related to the collaborative aspect of performance in this assessment is the concentration of immigrant students in a student's school. Non-immigrant students tend to perform better in the collaboration-specific aspects of the assessment when they attend schools with a larger proportion of immigrant students. This result cannot be generalised to socio-economic diversity within schools, however. Education systems should investigate whether, in their own context, diversity and students' contact with those who are different from them and who may hold different points of view can aid in developing collaboration skills.

\section{Boys need help in developing stronger collaboration skills, but don’t forget girls.}

Girls outperform boys in collaborative problem solving in every education system, both before and after accounting for performance in science, reading and mathematics. The relative size of the gender gap in collaborative problem-solving performance is even larger than it is in reading, where girls also outperform boys in every education system. This gender gap contrasts with that in the PISA 2012 individual problem-solving assessment, where boys outperform girls.

Girls are found to hold more positive attitudes towards relationships, meaning that they tend to be interested in others' opinions and want others to succeed. Boys, on the other hand, are found to hold more positive attitudes towards teamwork: they see the instrumental benefits of teamwork and how collaboration can help them work more effectively and efficiently. As positive attitudes towards collaboration - whether towards relationships or towards teamwork - are positively correlated with the collaboration-related component of performance in this assessment, education systems should look into fostering boys' appreciation of others.

However, although girls outperform boys, on average, there is a large overlap in their score distribution, with many girls also attaining only low levels of proficiency in collaborative problem solving. Schools should support both boys and girls who have trouble in forming healthy, positive and mutually supportive relationships with others. 
Attitudes towards collaboration and performance in collaborative problem solving Score-point difference in performance between those who agreed/strongly agreed with each statement and those who disagreed/strongly disagreed with the statement, OECD average

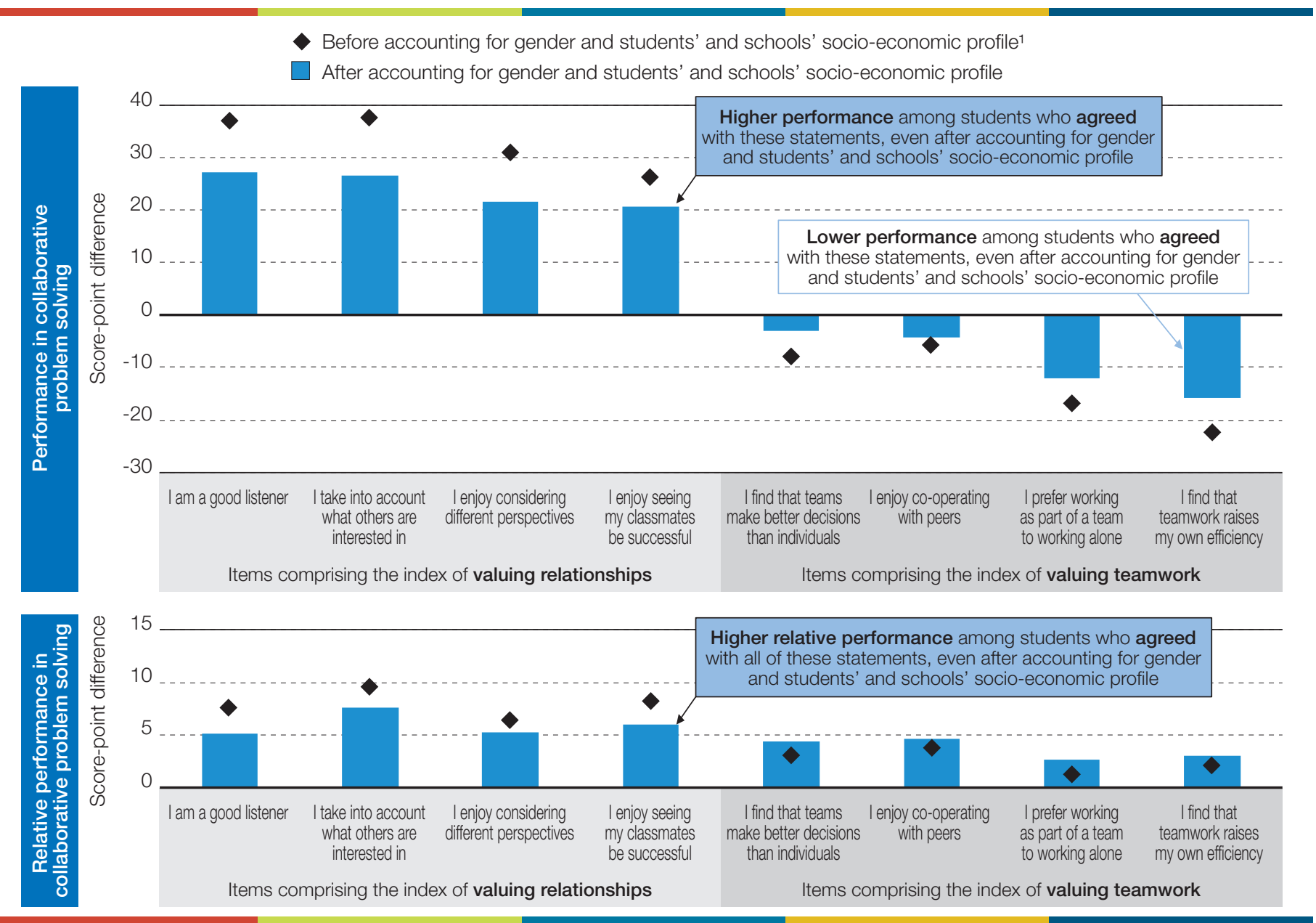

1. The socio-economic profile is measured by the PISA index of economic, social and cultural status (ESCS).

Notes: All differences are statistically significant (see Annex A3)

Relative performance refers to the residual performance, attributable to purely "collaborative problem-solving" competencies, after accounting for performance in science, reading and mathematics in a regression performed across students nationally.

Statements about attitudes towards collaboration are ranked in descending order of the score-point difference in collaborative problem solving between students who agreed/strongly agreed and those who disagreed/strongly disagreed with the above statements.

Source: OECD, PISA 2015 Database, Tables V.5.2a-h.

\section{The quality of the learning environment at school can influence students' attitudes towards collaboration.}

Results show that students who establish more positive relationships with their peers, teachers and parents tend to score higher in collaborative problem solving, and so do other students in the school. The good news is that most students, teachers and principals reported a positive learning environment in their schools. But too many students reported that they feel isolated at school, are bullied repeatedly or are treated unfairly by teachers. Schools can help by identifying students who are socially isolated, organising activities to foster constructive relationships at school, providing teacher training on classroom management, and adopting a whole-of-school approach to prevent bullying.

\section{How can students develop strong relationships? On line, at home, but not through video games.}

One way in which children develop relationships is on line, through Internet chat rooms or social media. In the past, students would meet friends face-to-face during the lunch break or after school, or would call them and talk on the phone 
from home. Today, students use Facebook, WeChat, WhatsApp, Twitter, Instagram, and other applications to get in immediate touch with their friends. If their friends are not on line, they can leave messages that their friends can read whenever they log on again.

This might seem like a superficial method of developing relationships, one that goes against the received wisdom that it is the time spent together that forges friendships. But in an increasingly virtual world, perhaps today's children are inadvertently training themselves to become better collaborative problem solvers simply by going on line.

Another way through which students can develop stronger relationships without leaving their own home is to develop better relationships with those at home. Many students do chores or take care of a family member. These tasks might allow them to develop a greater sense of responsibility towards others, as their family members count on them to contribute to the household. Spending time with the family members whom one is caring for also gives students an opportunity to develop relationships with others - much like the concept of "opportunity to learn" in the core PISA subjects.

But the evidence from PISA also shows that students who play video games perform worse in the collaborative elements of the assessment than students who do not, something that is seen in almost every participating education system. In contrast, students who use the Internet, chat or social networks outside of school score as well as, if not better than, students who do not. And while students who use the Internet, chat or social networks, play video games, or work in the household or take care of family members all value teamwork more than students who do not, students who use these online forms of communication or who help out at home are also more likely to value relationships, while students who play video games are less likely to value relationships.

Participation in these activities is typically beyond the reach of the school curriculum. Each of these activities also comes with consequences not necessarily related to collaboration. For example, the proliferation of online networks means that students can continue to be bullied while at home, while in the past, bullying mostly ended once students left school grounds. Policy makers should consider the benefits and drawbacks of each of these activities (using the Internet, chat rooms and social networks; working in the household and taking care of family members; playing video games) and what they mean for children's collaboration skills and their ability to use these skills to solve problems.

\section{Activities before and after school, and performance in collaborative problem solving}

Difference in collaborative problem-solving performance between students who reported that they had engaged in these activities before or after school and those who reported that they had not, OECD average

- Before accounting for performance in the three core PISA subjects, gender, and students' and schools' socio-economic profile

After accounting for performance in the three core PISA subjects, gender, and students' and schools' socio-economic profile

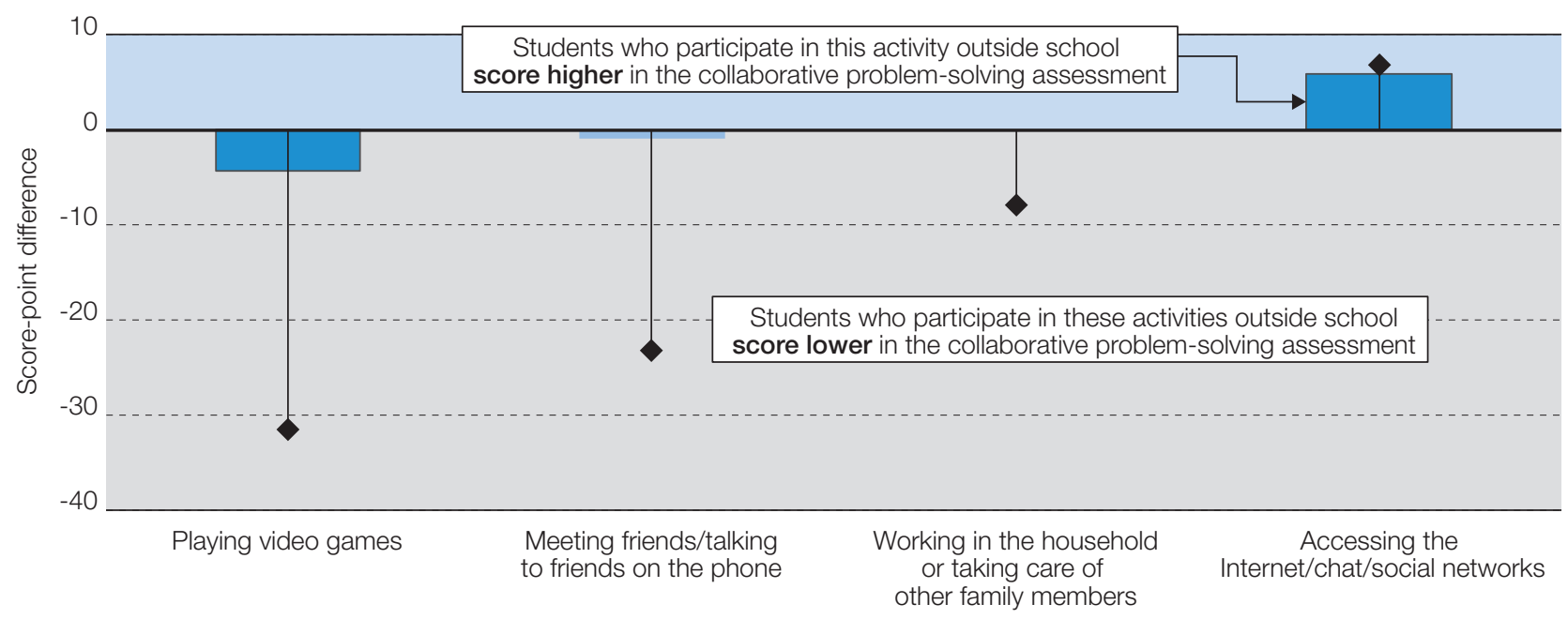

1. The socio-economic profile is measured by the PISA index of economic, social and cultural status (ESCS).

Notes: Score-point differences that are statistically significant are shown in a darker tone. All differences before accounting for performance in the three core PISA subjects, gender, and students' and schools' socio-economic profile are statistically significant (see Annex A3).

Students were asked whether they had engaged in these activities before or after school on the most recent school day prior to the PISA assessment. Activities are ranked in ascending order of the score-point difference in collaborative problem solving, after accounting for performance in the core PISA subjects, gender, and students' and schools' socio-economic profile.

Source: OECD, PISA 2015 Database, Tables V.6.7a-d. 


\section{For more information}

Contact: Jeffrey Mo (Jeffrey.Mo@oecd.org)

See: OECD (2017), PISA 2015 Results Nolume III): Students' Well-Being, OECD Publishing, Paris, http://dx.doi.org/10.1787/9789264273856-en.

OECD (2017), PISA 2015 Results Nolume V): Collaborative Problem Solving, OECD Publishing, Paris, http://dx.doi.org/10.1787/9789264285521-en.

Coming next month: Is too much testing bad for student performance and well-being?

This paper is published under the responsibility of the Secretary-General of the OECD. The opinions expressed and the arguments employed herein do not necessarily reflect the official views of OECD member countries.

This document, as well as any data and map included herein, are without prejudice to the status of or sovereignty over any territory, to the delimitation of international frontiers and boundaries and to the name of any territory, city or area.

The statistical data for Israel are supplied by and under the responsibility of the relevant Israeli authorities. The use of such data by the OECD is without prejudice to the status of the Golan Heights, East Jerusalem and Israeli settlements in the West Bank under the terms of international law.

This work is available under the Creative Commons Attribution-NonCommercial-ShareAlike 3.0 IGO (CC BY-NC-SA 3.0 IGO). For specific information regarding the scope and terms of the licence as well as possible commercial use of this work or the use of PISA data please consult Terms and Conditions on www.oecd.org. 